\title{
Rapid reductive degradation of azo and anthraquinone dyesby nanoscale zero-valent iron
}

Suvanka Dutta ${ }^{1}$, Rajnarayan Saha ${ }^{1, *}$, Harjyoti Kalita ${ }^{2,3}$, Achintya N. Bezbaruah ${ }^{3}$

${ }^{1}$ Department of Chemistry, National Institute of Technology, Durgapur, West Bengal 713209, India; ${ }^{2}$ Hilmar Cheese Company, PO Box 910, Hilmar, CA95324, USA; ${ }^{3}$ Nanoenvirology Research Group, Department of Civil and Environmental Engineering, North Dakota State University, Fargo, ND 58105, USA.

*Corresponding author. E-mail: rajusaharupa@yahoo.com, Phone: +91-9434788063 


\begin{abstract}
The presence of residual dyesin textile effluent is not desired as they are very toxic to the ecosystem components and carcinogenic in nature. The removal of reactive azo dye Remazol Brilliant Orange 3RID (RBO3RID) and anthraquinone dye Reactive Blue MR (RBMR) by nanoscale zero-valent iron (NZVI) particles was investigated in this study. The dyes were degraded up to 97\%by NZVI particles under different experimental conditions likeNZVI dosages (0.15-0.3 g/L), initial dye concentrations (100-500 mg/L), and pH values (2-12). NZVIwas found to work the best in the $\mathrm{pH}$ range of 8-12 which is the typical range of $\mathrm{pH}$ in textile wastewater. One gram of NZVI could remove up to 2757mg of RBO3RID dye and $2207 \mathrm{mg}$ of RBMR dye, and more than $80 \%$ dye removal was achieved within the first 15 minutes of reaction. FT-IR analyses showed the end products after the degradation are amines.
\end{abstract}

\title{
Key Words
}

Nanoparticles; Wastewater; Nanoscale zero-valent iron; reactive textile dye; Reactive Blue MR; Remazol Brilliant Orange 3RID; textile effluent

\section{1. Introduction}

2 Dyes used in textile industries find their way to the environment via wastewater.The textile 3 industry utilizesmanydyesand new dyes have been developed for better fixation onto the 4 fabrics(Kasiri and Safapour, 2014; Lewis, 2014; Holme, 2002). More than 100,000 types of 5 synthetic commercial dyes ( 700,000 tons) are used in the world every year(Basturk and 6 Karatas, 2015). Up to $15 \%$ of the dyesfinds its way tothe wastewater streams(Basturk and 
7 Karatas, 2015). Beingchemically very reactive, the dyesareharmful to the ecosystem components

8 at macro and molecular levels(Leme et al., 2015)and are known carcinogens(Alves de Lima et

9 al., 2007). Further, degradation products from dyes may be toxic to aquatic life and even 10 carcinogenic to human(Gao et al., 2010). Most textile dyes are known for their photo and heat 11 stability and do not degrade easily in the environment(Basturk and Karatas, 2015).

12 The textile wastewaters from the cotton mill are characterized by high chemical oxygen 13 demand (COD) (650-2100 mg/L)and low 5-day biochemicaloxygen demand $\left(\mathrm{BOD}_{5}\right)$ with low 14 BOD/CODratio ( 0.10) (Sun and Sun, 2015)and, as such, is not easily biodegradable.Wool and 15 cotton fabric dying units may have even higher COD values ( 7900 and $1100-4600 \mathrm{mg} / \mathrm{L}$, 16 respectively) (Bisschops and Spanjers, 2003).

17 During the past years, many physicochemical processes for the treatment of dye18 containing wastewaters have been reported. Electrocoagulation is one of the main 19 processesbeing promoted fortextile dye removal(Kobya et al., 2014) but it is chemicaland energy 20 intensiveand producesa significant amount of toxic sludge.Adsorption is also not an effective and 21 attractive mechanism for dye removaleven with innovative adsorption medium (Gao et al., 2010;

22 Gao et al., 2015).Membrane filtration is highly effective butgenerateshighly toxic concentrates 23 and iscost prohibitive and may foul membranes easily (Chidambaram et al., 2015). Pazdzior et 24 al. (2015)proposed an integrated process where concentrate from the membrane process was 25 treated biologically (90\% removal of color). Advanced oxidation processes that use 26 ozonation(Panda and Mathews, 2014), ultra-violet/ hydrogen-per-oxide (Basturk and Karatas, 27 2015), and Fenton oxidation (Soares et al., 2015) are also effective in dye removal, but they are 28 not economical and easy to use in most cases. On the other hands, biodegradation of dye is a 29 challenge not only because of the low BOD/COD ratio but also the presence of metals, 
metalloids, salts, and other toxicants (Imran et al., 2015). Conventional and innovative biological

31 processes have been tried including adsorbent assisted biodegradation using sequencing batch

32 reactor (SRB)(Santos and Boaventura, 2015), aerobic-anaerobic bacteria (Popli and Patel, 2015),

33 and packed bed reactor using a consortium of bacteria (Patel and Gupte, 2015). While biological

34 processes work to certain extent and they are difficult to be sustained in textile wastewater.

Azo dyes are a group of popular dyes used in textile industries, and their removal from wastewater has been extensively studied (Popli and Patel, 2015). Anthraquinone dyes are the

37 new group very popular dyes in the industry because of their bright color, high fixation rate, and 38 strong color fastness (Basturk and Karatas, 2015). However, as discussed earlier, there are no 39 established and accepted technology for textile dye treatment and most of the methods are either 40 very slow or technology intensive. Given the limitations of the current technologies there is a 41 need to develop efficient technologies for textile effluent treatment with specific emphasis on

42 dyes. Azo dyes are extensively studied and literature data can be used to compare new 43 technologies with the current ones. On the other hand limited studies have been conducted on the 44 degradation of anthraquinone dyes.

45 Zero-valent iron (ZVI) has been reported to decolorize azo dye solution via reduction of 46 the azo bond $(\mathrm{N}=\mathrm{N})$ through surface mediated reaction (Phukan et al., 2015). The cleavage of 47 the azo bond $(\mathrm{N}=\mathrm{N})$ in the chromophore of an azo dye leads to decolorization of the dye solution. 48 ZVI was also used to degrade anthraquinone dyes (He et al., 2012). He et al. (2012) concluded 49 that chromophores of dyes were destroyed during the decolorization process along with the 50 transformation of amino and aromatic rings.

51 Nanotechnology is an emerging area and has been used for textile dye removal with 52 varying degree of success. Abbasi et al. (2008) reported the $\mathrm{TiO}_{2}$ nanoparticle use for Basic Blue 
5341 degradation and Das et al, 2014 used Pd nanoparticles for the removal of Azo dyes.

54 However, these and other recent work need additional chemical addition (e.g., $\mathrm{H}_{2} \mathrm{O}_{2}$,

55 borohydride) and/or energy (e.g., sonication, UV radiation). There are also concerns about the

56 fate and transport of the nanomaterials used. Nanoscale zero-valent iron (NZVI) has been used

57 by authors for environmental contaminant remediation because it is relatively non-toxic to the

58 ecosystem components (Almeelbi and Bezbaruah, 2012; Krajangpan et al., 2012; Bezbaruah et

59 al., 2011). NZVI has been used for the removal of various textile dyes. Azo dyes like Acid Blue

60 A, Methyl Orange, Sunset Yellow (Rahman et al. 2014), Reactive Yellow K-RN (Mao et al.

61 2015), Acid Blue 113 (Shu et al. 2016), Reactive Black 5, Reactive Red 198, and Blue Black R

62 were treated NZVI and with $\mathrm{Pd}$ and $\mathrm{TiO}_{2}$ nanoparticles(Satapanajaru et al., 2011). Azo dye

63 Congo Red treatment with NZVI was reported and the end products were demineralized with

64 added Fenton reaction (Shih and Tso, 2012). Compared to azo dyes research, anthraquinone dye

65 degradation with NZVI is not extensively tried. In the recent years Cheng et al. (2015) have

66 studied degradation of an anthraquinone dye (Reactive blue 19) with CMC embedded NZVI. He

67 et al. (2012) has done a comparative degradation study for azo, anthraquinone and 68 triphenylmethane dyes. NZVI has much higher surface area $\left(25-52 \mathrm{~m}^{2} / \mathrm{g}\right)$ compared to

69 microscale ZVI (1-2 $\left.\mathrm{m}^{2} / \mathrm{g}\right)$ (Thompson et al., 2010). The dye removal mechanism being surface

70 area mediated, it is expected that higher dye removal will be achieved with NZVI than with non-

71 nano ZVI. This study uses NZVI for the degradation of azo and anthraquinone dyes in oxic

72 conditions and under the influence of different operational parameters (e.g., reaction time, initial

73 dye concentration, and $\mathrm{pH}$ ). The degradation byproducts are analyzed using FT-IR and the

74 mechanismsof dye removalby the nanoparticles are elucidated. 


\section{Experimental Section}

\subsection{Chemicals}

79 Two reactive dyes were used in this study (Table 1). Other chemicals were received from

80 various suppliers. The dyes and other chemicals were used in the experiments as receivedunless

81 otherwise specified.

82

\section{$83 \quad 2.2$ Synthesis of NZVI}

84 NZVI particles were synthesized by following the method developed by Krajangpan et al., 2012, 85 and this method is modified for increasing the stability of the NZVI. This synthesis is a bottom 86 up approach using ethanol water system without maintaining the inert conditions (Wang et al., 87 2006, Yuvakkumar et al., 2011). Ethanol was chosen because of its hygroscopic nature and its 88 higher dissolved oxygen solubility, so addition of ethanol causes a reduction in oxidation of the 89 nanoparticles by forming a protective layer on the outer sphere of the nanoparticles. Moreover, 90 other researches already established that ethanol can serve both as solvent and reducing agent 91 (Pal et al., 2009). Reduction of ethanol is two-step process, in the 1st step acetaldehyde forms

92 and in the second step it further reduced to acetic acid. It is also noted that the intermediate 93 acetaldehyde is less stable, and is stronger reductant than ethanol (Wang 2013). Though 94 reduction potential of ethanol water system is not enough for reduction of $\mathrm{Fe}^{3+}$ to $\mathrm{Fe}^{0}\left(\mathrm{E}_{0}=-0.04 \mathrm{~V}\right.$ 95 vs SHE), it can maintain effective reducing environment to prevent further oxidation of $\mathrm{Fe} 0$ in 96 open air (Yuvakkumar et al., 2011).

$972 \mathrm{Fe}^{2+}+\mathrm{BH}_{4}{ }^{-}+3 \mathrm{H}_{2} \mathrm{O} \rightarrow 2 \mathrm{Fe}^{0}+\mathrm{H}_{2} \mathrm{BO}_{3}{ }^{-}+4 \mathrm{H}^{+}+2 \mathrm{H}_{2}$ 


\subsection{Experimental:}

100 Each dye $(1 \mathrm{~g})$ was separately dissolved in $1 \mathrm{~L}$ of distilled water to prepare $1000 \mathrm{mg} / \mathrm{L}$ stock 101 solutions. Stock dye solutionswere diluted to prepare working solutions with desired 102 concentrations (100-500 mg/L). Borosilicate glass bottles (100 mL) fitted with rubber septum 103 were used as the reactors. Dye solutions $(100 \mathrm{~mL})$ and NZVI(0.15-0.3 g/L) were added to each 104 reactor prior to $\mathrm{pH}$ was adjustment $(\mathrm{pH}=2-11)$. The contents in the reactorswere briefly 105 sonicatedin an ultrasonic bath to ensure proper dispersion of the nanoparticles. The reactors were 106 rotated in a shaker to reduce mass transfer resistance on the nanoparticle surface. Sacrificial 107 reactors (in triplicate) were withdrawn at specific time intervals (2. 4, 6. 8, 10, 15 and 20 min) 108 and allowed to sit for a brief period before withdrawing samples. The samples were filtered and 109 the filtered samples were stored in a refrigerator and analyzed within $24 \mathrm{~h}$. Controls were run 110 with only dye (no NZVI) and samples collected, prepared, and stored the same way (as samples 111 with NZVI) for analysis.

\subsection{Analysis and characterization:}

114 The dye concentration was measured using a UV-VIS spectrophotometer (1601SHIMADZU) at $115492 \mathrm{~nm}$ and $596 \mathrm{~nm}$ wavelengths for RBO3RID dye and RBMR dye,respectively. Calibration 116 was done before and after each day's measurements and the average values were used to plot the 117 calibration curve. The calibration curve was used to determine dye concentrations in samples. 118 The $\mathrm{pH}$ and oxidation reduction potential (ORP) values were monitored simultaneously. The 119 ORP values are corrected for $\mathrm{pH}$ and reported in $\mathrm{mV}$ with reference to hydrogen electrode $\left(\mathrm{E}_{\mathrm{h}}\right)$ at $120 \mathrm{pH}$ 7.00. The Fourier transform infrared spectra of the dyes and degraded products were recorded

121 on a Thermo Nicolet iS10 spectrometer using $\mathrm{KBr}$ pellets in the range $4000-400 \mathrm{~cm}^{-1}$. X-ray 
122 diffraction (XRD) was done a Panalytical X'Pert Diffractometer, in the scan range of $35-100^{\circ}$

123 20with a scan speed of $1.2^{\circ} \mathrm{min}^{-1}$.Micrographs of NZVI particles were taken using a high

124 resolution transmission electron microscope (HRTEM, Technai TF20 ST) operated at $200 \mathrm{KV}$.

125 Prior to the grid preparation for TEM analysis the sample was dispersed in ethanol for $8 \mathrm{~h}$, and 126 then 2-3 drops of the NZVI in ethanol solution were placed onto a copper grid. The samples were 127 then put in a vacuum hood till the ethanol was evaporated completely and were analyzed using 128 the TEM.

\section{Results and discussion}

\subsection{Characterization:}

133 The synthesized iron nanoparticles were spherical in shape (Fig.1a). The particle diameter was 134 found to be $<35 \mathrm{~nm}$ (Fig.1b) with an average diameter of $16.46 \pm 5.98 \mathrm{~nm}(\mathrm{n}=116)$. The TEM 135 image shows that most particles formed aggregates. XRD plot shows a peak at $45^{\circ}$ (a smaller 136 peaks at $64^{\circ}$ and at $82^{\circ}$ ) representing the presence of $\mathrm{Fe}^{0}$ in the NZVI particles (Fig.1c).Small 137 amounts of oxides can also be seen. Others, however, reported $\sim 16 \%$ oxide presence based on 138 Energy-dispersive X-ray spectroscopy even though they found no oxide peak with $139 \mathrm{XRD}($ Krajangpan et al., 2012).

\section{3.2. Effects of reaction time:}

142 For a $50 \mathrm{mg} / \mathrm{L}$ initial dye concentration of both RBO3RID and RBMR dye, a removal efficiency 143 of $~ 79 \%$ was observed after the first 2 min and 98\% within 15 min with $0.2 \mathrm{~g} / \mathrm{L}$ NZVI dose. 144 Only marginal removal was observed beyond 15 min of reaction time.Absorbance peaks of these 
145 dye solutions in the visible region (400-700 nm) disappeared after treatment with NZVI (Fig. 2a-

146 b). In aqueous medium, NZVI particles dissociate into ferrous ions $\left(\mathrm{Fe}^{0}+2 \mathrm{H}_{2} \mathrm{O} \rightarrow \mathrm{Fe}^{2+}+\mathrm{H}_{2}+\right.$

$\left.147 \mathrm{OH}^{-}\right)$, thereby releasing two electrons. The released electrons can rapidly combine with certain

148 organic compounds present in the medium, resulting in reduction of the organic compound.

149 NZVI is known to breakdown the dye via reductive degradation (Cao et al., 1999) and in the

150 present case the azo group in the dye molecule is reduced. With the same NZVI dose $(0.2 \mathrm{~g} / \mathrm{L})$

151 the profile of dye concentration reduction versus time for various dye concentrations (Fig.3a-b)

152 indicate that same pattern of degradation (very rapid initially and then slower) was achieved

153 irrespective of dye concentration. The decreasing absorbance peak at the $\lambda_{\max }$ (Fig.2a-b)

154 indicated that chromophore group was broken down. Azo bond $(\mathrm{N}=\mathrm{N})$ was reported to be

155 degraded by zero valent iron in Acid Orange 2(Cao et al., 1999), Reactive Black 8 (Feng et al., 156 2000), Acid Blue 113 (Nam and Tratnyek, 2012), Acid Red 14 and 18 (Samarghandi et al., 157 2012), Reactive Black 5, and Reactive Red 198 (Satapanajaru et al., 2011). The absorbance 158 peak from the azo group was reduced in UV/VIS chromatograph after treatment by 159 NZVIindicating degradation of the dye (Fig.2a-b).

161 3.3. Effects of initial dye concentrationand NZVIdose:

162 Dye removal efficiency varied with the initial dye concentration (100 to $500 \mathrm{mg} / \mathrm{L}$ ) and NZVI 163 dose (0.15 to $0.30 \mathrm{~g} / \mathrm{L})$ (Fig.4a-b). For 0.15 gNZVI/L dose, the removal efficiency decreased 164 from 96 to 73\% for RBO3RID dye (Fig.4a) and from 97 to 66\% for RBMR dye (Fig. 4b) when 165 initial dye concentration was increased from 100 to $500 \mathrm{mg} / \mathrm{L}$. The decrease in removal was 166 modest (only 2.29\%) for RBO3RID dye with $0.20 \mathrm{~g}$ NZVI/L dose while the decrease was still 167 very prominent with RBMR dye ( 20\%) when the dye concentration was changed from 100 to 
168 169

171

\section{3.4. Unit Removal Capacity (URC):}

173 Unit removal capacity (URC) is calculated based on the removed amount of dyes per unit weight 174 of NZVI particles. Each gram of NZVI particles removed 634, 1261, 1864, 2466 and $2757 \mathrm{mg}$ 175 RBO3RID dye and 645, 1215, 1594, 2045 and 2207 mg RBMR dye when the initial dye 176 concentrations were 100, 200, 300, 400 and 500 mg/L, respectively (Fig.4a and 4b). The higher 177 NZVI doses achieved higher dye removals. However, they had lower URCs at the same initial 178 dye concentration. Above NZVI dosage of $0.25 \mathrm{~g} / \mathrm{L}$, the URC values reach saturation (Fig. 4a 179 and 4b). Increasing the NZVI dosage beyond this value has little effect on URC. These 180 observations show that the URC increases with increasing dye concentration and proves that 181 NZVI a potential reactive media for dye removal.
$500 \mathrm{mg} / \mathrm{L}$. For 0.25 and $0.30 \mathrm{~g} \mathrm{NZVI/L}$, there was marginal (0.07- 0.1\%) decrease in removal efficiency for RBO3RID dye with incease in dye concnetration. The removal efficiency decrease was marginal (1.3\%) for RBMR dye with $0.30 \mathrm{~g} \mathrm{NZVI/L.}$

\section{5. pH and ORPChanges:}

Oxidation-reduction potential and $\mathrm{pH}$ were monitored during the batch studies with $50 \mathrm{mg} / \mathrm{L}$ dye concentration and 0.2 g/L NZVI. During the study, ORP $\left(E_{h}\right)$ dropped (Fig. 5) from initial +418 to $-220 \mathrm{mV}$ quickly (within $3.5 \mathrm{~min}$ ), and then there was a slower decrease to $-349 \mathrm{mV}$ in about $30 \mathrm{~min}$. ORP increased to $-208 \mathrm{mV}$ in $\sim 90 \mathrm{~min}$. Reductive conditions were attained within $1 \mathrm{~min}$ of starting the experiment and continued till much beyond the dye degradation study period (90 min) used in this work.Within the NZVI reaction system there are several factors which play roles in lowering the ORP value. Along with consumption of reducible contaminant and 
191 consequent removal of oxygen, generation of $\mathrm{Fe}^{2+} / \mathrm{Fe}^{3+}$ species and $\mathrm{H}_{2}$ evolution are the main 192 reason for the drop in ORP (Shi et al. 2011).Major $\mathrm{pH}$ variation was also detected during the 193 reaction.pH increased sharply from initial 2.5 to 8.0 within the first $8 \mathrm{~min}$, and then remained 194 more or less constant till the end of the observation (90 min, $\mathrm{pH}=8.1)$. The $\mathrm{pH}$ increase was 195 because of hydroxyl ions generation during NZVI's reaction with water $\left(\mathrm{Fe}^{0}+2 \mathrm{H}_{2} \mathrm{O} \rightarrow\right.$ $196 \mathrm{Fe}^{2+}+\mathrm{H}_{2}+2 \mathrm{OH}^{-}$(Shu et al., 2010).

\subsection{Effects of $\mathrm{pH}$}

$199 \mathrm{pH}$ playsan important role in dye removal by zero-valent iron.Here in this study, $\mathrm{pH}$ was 200 adjusted adding $\mathrm{NaOH}$ solution $(1.0 \mathrm{~N})$ or $\mathrm{HCl}(1.0 \mathrm{~N})$ to change the $\mathrm{pH}$ of the solution. While 201 maximum RBO3RID dye removal (94-98\%) was achieved in the pH range of 3-9 (Fig. 6a), the 202 removal efficiencies significantly dropped at low (pH 2, 62\%) and high $\mathrm{pH}(\mathrm{pH} 10-13,44-49 \%)$.

203 The efficiencies of RBMR dye removal (Fig. 6b) at lower (pH 2, 61\%) and higher $\mathrm{pH}(\mathrm{pH} 12-$ 204 13, 55-61\%) got equallyaffected while dye removal efficiencies remained high for in the $\mathrm{pH}$ 205 range of 3-11 (86-97\%).Low decolorization of the test solution was observed in alkaline pH. 206 Oxidized iron (corrosion products) on the surface of the NZVI particles gave a reddish color to 207 the solution. The hydroxides generated also occupy the reactive sites on the NZVI surface and 208 hinder the (dye degradation) reaction(Shu et al., 2007). The corrosion products are also known to 209 causemass transport limitations from NZVI surface to the active core $\left(\mathrm{Fe}^{0}\right)$ of the particles. 210 Ferrous ions dissolve out from the iron surface (Eq. 2 and 3) and combine with hydroxyl ions 211 present in the reaction medium to form ferrous hydroxide, and the hydroxide is precipitated on

212 the iron NZVI surface blocking the reactive sites (Shu et al., 2009). The moderately low pH 213 helps in removing the passivating layer of iron oxides from the NZVI surface (Almeelbi and 
214 Bezbaruah, 2012; Shu et al., 2010) and, thus, exposing the core $\mathrm{Fe}^{0}$ to react with the dyes. The

215 charge on the surface also changes from positive to negative with an increase in solution $\mathrm{pH}$

216 (Almeelbi and Bezbaruah, 2012; Satapanajaru et al., 2011).

$217 \mathrm{Fe}^{0}+2 \mathrm{H}_{2} \mathrm{O} \rightarrow \mathrm{Fe}^{2+}+\mathrm{H}_{2}+2 \mathrm{OH}^{-}$

$218 \mathrm{Fe}^{0}+\mathrm{H}_{2} \mathrm{O}+0.5 \mathrm{O}_{2} \rightarrow \mathrm{Fe}^{2+}+\mathrm{H}_{2}+2 \mathrm{OH}^{-}$

219 This means that acidic conditions favours reduction process. Low $\mathrm{pH}$ range may remove the 220 passivating layers off the NZVI core (Shu et al., 2009; Satapanjaru et al., 2008), rendering the 221 nanoparticles free to react with the azo group in the dye molecules. This result may also be 222 ascribed to the $\mathrm{pH}_{\text {zpc }}$ (zero point charge) of NZVI. Li et al. (2007) indicated that the $\mathrm{pH}_{\mathrm{zpc}}$ of 223 NZVI is around 8. At a low $\mathrm{pH}\left(\mathrm{pH}_{\text {zpc }}\right)$ the NZVI surface has positive charge, and the dye 224 molecules, with a negative charge bearing $\mathrm{SO}_{3}{ }^{-}$group (Fan et al., 2009), attract the NZVI 225 particles towards themselves. Thus, the degradation reaction between the dye molecules and 226 NZVI could be achieved easily. On the other hand, at an alkaline $\mathrm{pH}$, the zero valent iron surface 227 might be covered by corrosion products formed under these conditions. This phenomenon causes 228 a lowering of the reducing power of NZVI and mass transport limitations on NZVI surface. The 229 charge of the surface also changes from positive to negative with an increase in solution $\mathrm{pH}$ 230 (Stumm et al., 1990). Moreover,in an extremely acidic ( $\mathrm{pH} \mathrm{2)}$ condition, poor dye removal 231 efficiencywas observed possibly becausethe NZVI particles were dissolved quickly in the bulk 232 solution resulting in a poorreaction media.

The dye degradation data obtained from the $\mathrm{pH}$ studies were analyzed for reaction order 234 and rate determination. The data were fitted into zero-, first-, and second-order reactions and it 235 was found that (pseudo)first reaction best describes the degradation reactions. For RBO3RID dye 236 the degradation reaction rate constant $(\mathrm{k})$ varied from $0.0104-0.3556 \mathrm{~min}^{-1}$ in the $\mathrm{pH}$ range 2-13 237 with the highest $\mathrm{k}$ at $\mathrm{pH} 5$ and the $\mathrm{k}$ value was between $0.0820-0.4730 \mathrm{~min}^{-1}$ for RBMR dye with 238 the highest k at pH 7 (see Table S1 and Table S2 in Supporting Information). The lowest k 239 values for both the dyes were observed at $\mathrm{pH} 13$. 


\subsection{Confirmation of dye degradation via FTIR spectroscopic Analyses:}

242 FT-IR analyses were done for both of the dyes and their degradation products. The degradation

243 products of the dyes were separated based on their solubility in water and methanol and 244 characterized using FT-IR (Fig. S1and Fig.S2, Supporting Information).

246 3.7.1 RBO3RID dye and its degraded products:

247 During FT-IR analysis of untreatedRBO3RID dye (Fig. 7a),stretchingswere observed at 3422 $248 \mathrm{~cm}^{-1}\left(v_{\mathrm{OH}}\right), 3273 \mathrm{~cm}^{-1}\left(v_{\mathrm{NH}}\right), 2850 \mathrm{~cm}^{-1}\left(v_{\mathrm{CH}}\right), 1671 \mathrm{~cm}^{-1}\left(v_{\mathrm{CO}}\right), 1498 \mathrm{~cm}^{-1}\left(v_{\mathrm{NN}}\right)$, and $1040 \mathrm{~cm}^{-}$

$249{ }^{1}\left(v_{\mathrm{SO}}\right)$.After reaction with NZVI for 60 min the treated dye did not display stretching at $1498 \mathrm{~cm}^{-}$ $250{ }^{1}\left(v_{\mathrm{NN}}\right)$ but new stretchings appeared at $3366 \mathrm{~cm}^{-1}($ Fig. $7 \mathbf{b})$ and $3350 \mathrm{~cm}^{-1}$ (Fig. 7c)for 251 corresponding primary amines which corroborates that breaking the $\mathrm{N}=\mathrm{N}$ bond during the 252 treatment with NZVI had taken place indicating cleavage of azo bond present in the parent dye 253 during the treatment with NZVI.

\section{3.7.2 RBMR dye and its degradation products:}

256 When analyzing RBMR dye before treatment, the stretchingswere observed at $3421 \mathrm{~cm}^{-1}\left(v_{\mathrm{OH}}\right)$, $2573288 \mathrm{~cm}^{-1}\left(v_{\mathrm{NH}}\right), 2950 \mathrm{~cm}^{-1}\left(v_{\mathrm{CH}}\right), 1718 \mathrm{~cm}^{-1}\left(v_{\mathrm{CO}}\right), 1040 \mathrm{~cm}^{-1}\left(v_{\mathrm{SO}}\right)$, and $1067 \mathrm{~cm}^{-1}\left(v_{\mathrm{SO}}\right)$ (Fig. 8a). 258 After treating the dye with NZVI for 60 min,water and methanol soluble part(Fig. 8b) of 259 degradation products displayed stretching at $1718 \mathrm{~cm}^{-1}\left(v_{\mathrm{CO}}\right), 3381 \mathrm{~cm}^{-1}$, and $3239 \mathrm{~cm}^{-1}\left(v_{\mathrm{NH}}\right)$ 260 whereas water insoluble degraded products (Fig. 8c) displayed stretchings at $3372 \mathrm{~cm}^{-1}$, and $2613231 \mathrm{~cm}^{-1}\left(v_{\mathrm{NH}}\right)$. FTIR of water soluble but methanol insoluble fraction (Fig.8d) did not display 262 any stretches of amine.These data corroborates that thefraction (Fig.8d) did not contain any 263 amine group but other 2 parts (Fig. 8b-c)were primary amine compounds which might be only 
264 possible by the breaking of $\mathrm{C}-\mathrm{N}$ bond from central benzene ring due to stabilization of benzoin

265 free radical. This was confirmed when methanol and water soluble part(Fig. 8d) displayed

266 stretching at $3448 \mathrm{~cm}^{-1}\left(v_{\mathrm{OH}}\right)$ and $1130 \mathrm{~cm}^{-1}, 1110 \mathrm{~cm}^{-1}\left(v_{\mathrm{sO}}\right)$.It may be inferred that the selected dye

267 had undergone degradation in such a way that it raptured its extended conjugation destroying the

268 chromophore.

269

\section{4. Conclusions}

271 In this study, efficient RBO3RID and RBMR dye degradation in aqueous solution was achieved 272 with nanoscale zero valent iron (NZVI) particles.The efficiency of dye removal depended on 273 NZVI dosage, initial dye concentration, and $\mathrm{pH}$ of the solution. RBO3RID and RBMR dye 274 removalwas negatively affected in extremely basic ( $\mathrm{pH}$ 12-13) or acidic conditions ( $\mathrm{pH}$ 2). 275 Irrespective of dye concentration or NZVI dosage,the most part of the degradation reaction 276 occurred within the first 15 min. Highest unit removal capacities (URCs) of RBO3RID and 277 RBMR dye were observed to be 2756.7 and $2207.33 \mathrm{mg}$ dye/g NZVI, respectively, when dye 278 concentration varied between 100 and $500 \mathrm{mg} / \mathrm{L}$. The FT-IR spectra showedthat bothazo dye and 279 anthraquinone degradation products were always the corresponding amines. For the 280 anthraquinone dye, the end productswere also found to be the corresponding amines. Based on

281 the observations in this study, it may be concluded that nanoscale zero-valent iron (NZVI) can be 282 a viable alternative for dye removal from textile mill wastewater.

283

284 Acknowledgements: This research was funded by National Institute of Technology, Durgapur, 285 India. Harjyoti Kalita (graduate student at the time of this research) was partially funded at North 
286 Dakota State University by a grant from National Science Foundation (Grant \# CMMI-1125674,

287 PI: Bezbaruah).

288 


\section{References}

Abbasi M, Asl NR. Sonochemical degradation of Basic Blue 41 dye assisted by nano $\mathrm{TiO}_{2}$ and $\mathrm{H}_{2} \mathrm{O}_{2}$. J Hazard Mater 2008;153: 942-47.

Almeelbi T, Bezbaruah A. Aqueous phosphate removal using nanoscale zero-valent iron. J Nanoparticle Res 2012; 14(7)

Alves de Lima RO, Bazo AP, Favero Salvadori DM, Rech CM, Oliveira DdP, Umbuzeiro GdA. Mutagenic and carcinogenic potential of a textile azo dye processing plant effluent that impacts a drinking water source. Mutation Res-Genetic Toxicol and Environ Mutagenesis 2007;626:53-60.

Basturk E, Karatas M. Decolorization of antraquinone dye Reactive Blue 181 solution by UV/ $\mathrm{H}_{2} \mathrm{O}_{2}$ process. J Photochem Photobiol a-Chemistry 2015;299:67-72.

Bezbaruah AN, Shanbhogue SS, Simsek S, Khan E. Encapsulation of iron nanoparticles in alginate biopolymer for trichloroethylene remediation. J Nanoparticle Res 2011;13:667381.

Bisschops I, Spanjers H. Literature review on textile wastewater characterization. Environ Technol.2003;24:1399-1411.

Cao JS, Wei LP, Huang, QG, Wang LS, Han SK. Reducing degradation of azo dye by zerovalent iron in aqueous solution. Chemosphere 1999;38:565-571.

Cheng Y, Lu M, Jiao C, Liu H-J. Preparation of stabilized nano zero-valentiron particles via a rheological phase reaction method and their use in dye decolourization, Environmental Technol. 2013; 34:4,445-451,

Chidambaram T, Oren Y, Noel M. Fouling of nanofiltration membranes by dyes during brine recovery from textile dye bath wastewater. Chem Engg J 2015; 262:156-168.

Das RS, Singh B, Mandal A, Banerjee R, Mukhopadhyay S. Homogeneous Palladium Nanoparticles Surface Hosts Catalyzed Reduction of the Chromophoric Azo (-N=N-) Group of Dye, Acid Orange 7 by Borohydride in Alkaline Media. Int J Chemical Kinetics 2014;46:746-58.

Fan J, Guo Y, Wang J, Fan M. Rapid decolorization of Azo dye methyl orange in aqueous solution by nanoscale zero valent iron particles, J Hazard Mater. 2009; 166 : 904-910.

Feng W, Nansheng D, Helin H. Degradation mechanism of azo dye C. I. reactive red 2 by iron powder reduction and photooxidation in aqueous solutions. Chemosphere 2000;41:123338.

Gao J, Si C, He Y. Application of soybean residue (okara) as a low-cost adsorbent for reactive dye removal from aqueous solution. Desalin Water Treat 2015;53:2266-77. 
Gao J, Zhang Q, Su K, Chen R, Peng Y.Biosorption of Acid Yellow 17 from aqueous solution by non-living aerobic granular sludge. J Hazard Mater 2010;174:215-225.

He Y, Gao J-F., Feng F-Q, Liu C, Peng Y-Z, Wang S-Y. The comparative study on the rapid decolorization of azo, anthraquinone and triphenylmethane dyes by zero-valent iron. Chem Engg J 2012;179: 8-18.

Holme I. Recent developments in colorants for textile applications. Surface Coatings Int Part BCoatings Trans. 2002;85:243-64.

Imran M, Crowley DE, Khalid A, Hussain S, Mumtaz MW, Arshad M. Microbial biotechnology for decolorization of textile wastewaters. Reviews in Environmental Sci and Bio-Technol 2015;14:73-92.

Kasiri MB, Safapour S. Natural dyes and antimicrobials for green treatment of textiles. Environ Chem Letters 2014;12:1-13.

Kobya M, Gengec E, Sensoy MT, Demirbas E. Treatment of textile dyeing wastewater by electrocoagulation using Fe and Al electrodes: optimisation of operating parameters using central composite design. Coloration Technol 2014;130(3), 226-35.

Krajangpan S, Kalita H, Chisholm BJ, Bezbaruah, AN. Iron Nanoparticles Coated with Amphiphilic Polysiloxane Graft Copolymers: Dispersibility and Contaminant Treatability. Environ Sci Technol 2012;46:10130-10136.

Leme DM, Rodrigues de Oliveira GA, Meireles G, Brito LB, Rodrigues LdB, de Oliveira DP. Eco- and Genotoxicological Assessments of Two Reactive Textile Dyes. J Toxicol Environ Health-Part A 2015;78:287-300.

Lewis DM. Developments in the chemistry of reactive dyes and their application processes. Coloration Technol. 2014;130:382-412.

Li Z, Jones HK, Zhang P, Bowman RS. Chromate transport though columns packed with surfactant-modified zeolite/zero valent iron pellets. Chemosphere. 2007; 63: 1861-1866.

Mao Y, Xi Z, Wang W, Ma C, Yue Q. Kinetics of Solvent Blue and Reactive Yellow removal using microwave radiation in combination with nanoscale zero-valent iron. J Environ Sci. 2015; 30;165-172

Nam S, Tratnyek PG. Reduction of azo dyes with zero-valent iron. Water Res 2000;34:18371845

Pal A, Shah S, Devi S. Microwave-assisted synthesis of silver nanoparticles using ethanol as a reducing agent. Mater. Chem. Phys. 2009; 114:530-532.

Panda KK, Mathews AP. Ozone oxidation kinetics of Reactive Blue 19 anthraquinone dye in a tubular in situ ozone generator and reactor: Modeling and sensitivity analyses. Chem Engg J 2014;255:553-567. 
Patel Y, Gupte A. Biological Treatment of Textile Dyes by Agar-Agar Immobilized Consortium in a Packed Bed Reactor. Water Environ Res 2015;87:242-251.

Pazdzior K, Klepacz-Smolka A, Ledakowicz S, Sojka-Ledakowicz J, Mrozinska Z, Zylla R. Integration of nanofiltration and biological degradation of textile wastewater containing azo dye. Chemosphere 2009;75:250-255.

Phukan M, Noubactep C, Licha T. Characterizing the ion-selective nature of Fe-0-based filters using azo dyes. Chem Engg J 2015;259:481-491.

Popli S, Patel UD. Destruction of azo dyes by anaerobic-aerobic sequential biological treatment: a review. Int J Environ Sci Technol 2015;12:405-20.

Rahman N, Abedin Z , Hossain MA. Rapid degradation of azo dyes using nano-scale zero valent iron. Am J Environ Sci. 2014; 10(2):157-163.

Samarghandi MR, Zarrabi M, Amrane A, Sepehr MN, Noroozi M, Namdari S, Zarei A. Kinetic of degradation of two azo dyes from aqueous solutions by zero iron powder: determination of the optimal conditions. Desalin Water Treat 2012;40:137-43.

Santos SCR, Boaventura RAR Treatment of a simulated textile wastewater in a sequencing batch reactor (SBR) with addition of a low-cost adsorbent. J Hazard Mater 2015;291:74-82.

Satapanajaru T, Chompuchan C, Suntornchot P, Pengthamkeerati P. Enhancing decolorization of Reactive Black 5 and Reactive Red 198 during nano zerovalent iron treatment. Desalin 2011;266:218-230.

Satapanajaru T, Anurakpongsatorn P, Pengthamkeerati P, Boparai H. Remediation of atrazinecontaminated soil and water by nano zerovalent iron. Water, Air, Soil Pollut. 2008; 192: 349-359.

Shih Y-H, Tso C-P. Fast Decolorization of Azo-Dye Congo Red with Zerovalent Iron Nanoparticles and Sequential Mineralization with a Fenton Reaction. Environ Engg Sci 2012; 29:929-33.

Shi Z, Nurmi JT, Tratnyek PG, Effects of Nano Zero- valent iron on Oxidation- Reduction Potential. Environ Sci Technicol. 2011; 45: 1586-1592.

Shu H-Y, Chang M-C, Yu H-H, Chen W-H. Reduction of an azo dye Acid Black 24 solution using synthesized nanoscale zerovalent iron particles. J Colloid Interface Sci 2007;314:89-97.

Shu H-Y, Chang MC, Chang CC. Integration of nanosized zero-valent iron particles addition with UV/H2O2 process for purification of Azo dye Acid Black 24 solution. J Hazard Mater 2009; 167: 1178-1184.

Shu H-Y, Chang M-C., Chen C-C, Chen P-E .Using resin supported nano zero-valent iron particles for decoloration of Acid Blue 113 azo dye solution. J Hazard Mater 2010;184:499-505. 
Shu H-Y, Chang M-C, Liu J-J, Reductive decolorization of acid blue 113 azo dye by nanoscale zero-valent iron and iron-based bimetallic particles, Desalination and Water Treatment 2016;57:7963-7975.

Soares PA, Batalha M, Souza SMAGU, Boaventura RAR, Vilar VJP. Enhancement of a solar photo-Fenton reaction with ferric-organic ligands for the treatment of acrylic-textile dyeing wastewater. J Environ Manage 2015;152:120-31.

Stumm W, Sulzberger B, Sinniger J. The coordination chemistry of the oxide- electrolyte interface- the dependence of the surface reactivity (dissolution, redox reactions) on surface structure, Croat Chem Acta. 1990; 63:277-312.

Sun F, Sun B, Hu J, He Y, Wu W. Organics and nitrogen removal from textile auxiliaries wastewater with A(2)O-MBR in a pilot-scale. J hazard mater 2015;286:416-24.

Thompson JM, Chisholm BJ, Bezbaruah AN. Reductive Dechlorination of Chloroacetanilide Herbicide (Alachlor) Using Zero-Valent Iron Nanoparticles. Environ Engg Sci 2010;27:227-32.

Wang W, Jin ZH, Li TL, Zhang H, Gao S. Preparation of spherical iron nanoclusters in ethanolwater solution for nitrate removal. Chemosphere, 2006;65(8) 1396-1404.

Wang JX, US Patent 20130264198 A1. Washington, DC: U.S. Patent and Trademark Office.

Yuvakkumar R, Elango V, Rajendran V , Kankan N. Preparation and characterization of zero valent iron nanoparticles. Digest J Nanomater Biostruct. 2011; 6 :1771-1776.

\section{List of Table}

Table 1. Details of the two commercial dyes used in this study 


\section{List of Figures}

Figure 1. Characteristics of freshly produced nanoscale zero-valent iron (NZVI) particles used in this study: (a) Transmission electron microscope (TEM) monograph of NZVI particles; (b) Particle size distribution of NZVI counted from TEM monographs. The average diameter was $16.46 \pm 5.98 \mathrm{~nm}(\mathrm{n}=116)$; and (c) X-ray Diffraction (XRD) spectra of the particles. Prominent peaks of $\mathrm{Fe}^{0}$ were observed.

Figure 2. Absorption spectra of dye during reaction at different time interval (0 to $30 \mathrm{~min}$ ): (a) RBO3RID dye; and (b) RBMR dye.

Figure 3. Residual dye concentration over time for various initial dye concentrations during treatment with NZVI: (a) RBO3RID dye; and (b) RBMR dye. NZVI concentration was 0.2 g/L $\mathrm{mg} / \mathrm{L}$ and $\mathrm{pH}$ was not adjusted. The vertical error bars are \pm standard deviations. The data points are joined by straight lines for ease of reading only and do not represent trendlines.

Figure 4. Dye removal efficiency of NZVI for different initial concentrations of (a) RBO3RID dye, and (b) RBMR dye. The vertical error bars are \pm standard deviations. The data points are joined by straight lines for ease of reading only and do not represent trendlines.

Figure 5. Change of $\mathrm{pH}$ and oxidation reduction potential (ORD) of RBO3RID dye solution (50 $\mathrm{mg} / \mathrm{L}$ over time in the presence of $0.2 \mathrm{~g} / \mathrm{L}$ of NZVI. The ORP values were corrected for $\mathrm{pH}$ and expressed as $\mathrm{mV}$ with standard hydrogen electrode at $\mathrm{pH}$ 7. ORP values indicate that the reaction took place under reduction conditions. Other dye showed similar pattern (data not shown).

Figure 6. Effect of $\mathrm{pH}$ on dye removal efficiency of NZVI (a) RBO3RID dye, and (b) RBMR dye. NZVI concentration was $0.2 \mathrm{~g} / \mathrm{L}$ and $\mathrm{pH}$ was not adjusted. The vertical error bars are \pm standard deviations. The data points are joined by straight lines for ease of reading only and do not represent trendlines.

Figure 7. FT-IR spectra of RBO3RID dye and before and after treatment with NZVI (0.2 g/L and $\mathrm{pH}$ was not adjusted): (a)PureRBO3RID dye, (b) Water insoluble degradation by-products, and (c) Water soluble degradation by-products.

Figure 8. FT-IR spectra of RBMR dye and before and after treatment with NZVI $(0.2 \mathrm{~g} / \mathrm{L}$ and pH was not adjusted): (a)PureRBMR dye, (b) Water soluble and methanol soluble degradation by-products, (c) Water insoluble and methanol soluble degradation by-products(d) Water soluble degradation by-products. 
Table 1.Details of the two commercial dyes used in this study

\begin{tabular}{|c|c|c|}
\hline Details & $\begin{array}{l}\text { Remazol Brilliant Orange } \\
\text { 3RID(RBO 3RID) }\end{array}$ & Reactive Blue MR(RBMR) \\
\hline Molecular Formula & $\mathrm{C}_{20} \mathrm{H}_{17} \mathrm{~N}_{3} \mathrm{Na}_{2} \mathrm{O}_{11} \mathrm{~S}_{3}$ & $\mathrm{C}_{23} \mathrm{H}_{12} \mathrm{Cl}_{2} \mathrm{~N}_{6} \mathrm{Na}_{2} \mathrm{O}_{8} \mathrm{~S}_{2}$ \\
\hline Molecular Weight & 617.54 & 681.39 \\
\hline Chemical structure & & \\
\hline Maximum absorbance $\left(\lambda_{\max }\right)$ & $492 \mathrm{~nm}$ & $596 \mathrm{~nm}$ \\
\hline C.I. No & 17757 & 61205 \\
\hline CAS No. & $2225-83-1$ & 13324-20-4/4499-01-8 \\
\hline Supplier & Colour Chem, Mumbai, India & Colour Chem, Mumbai, India \\
\hline
\end{tabular}



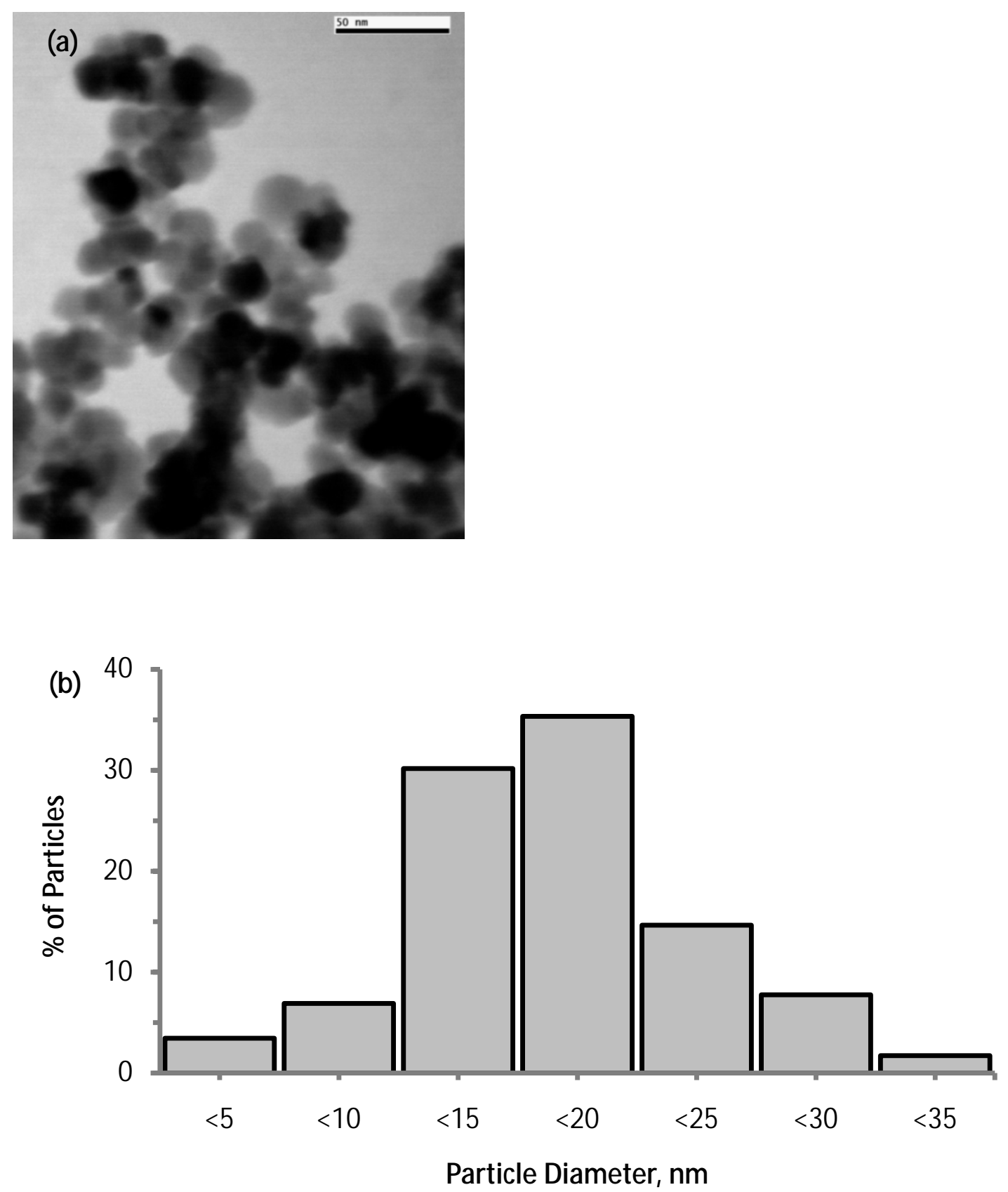

Figure 1. 


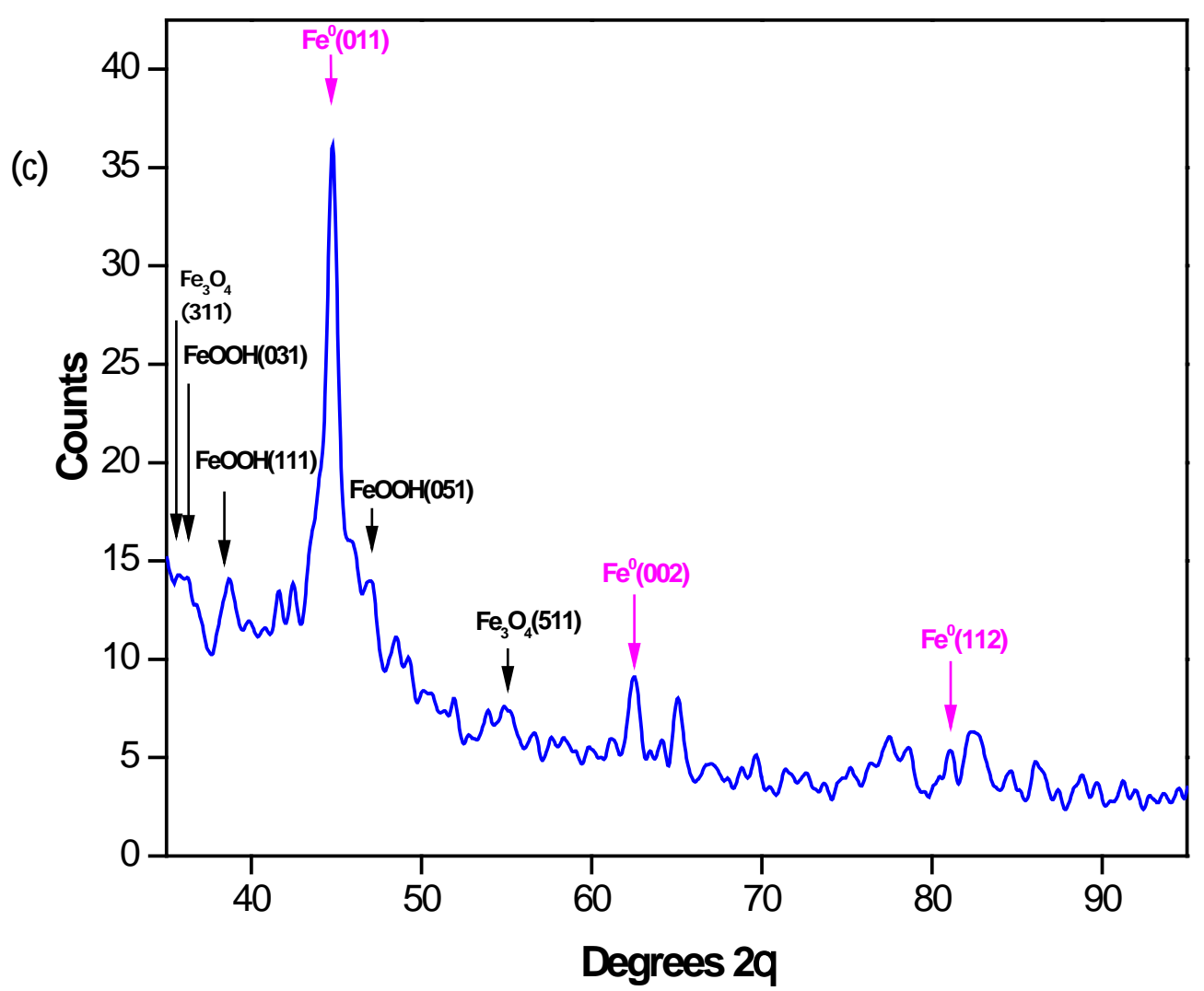

Figure 1. 
(a)

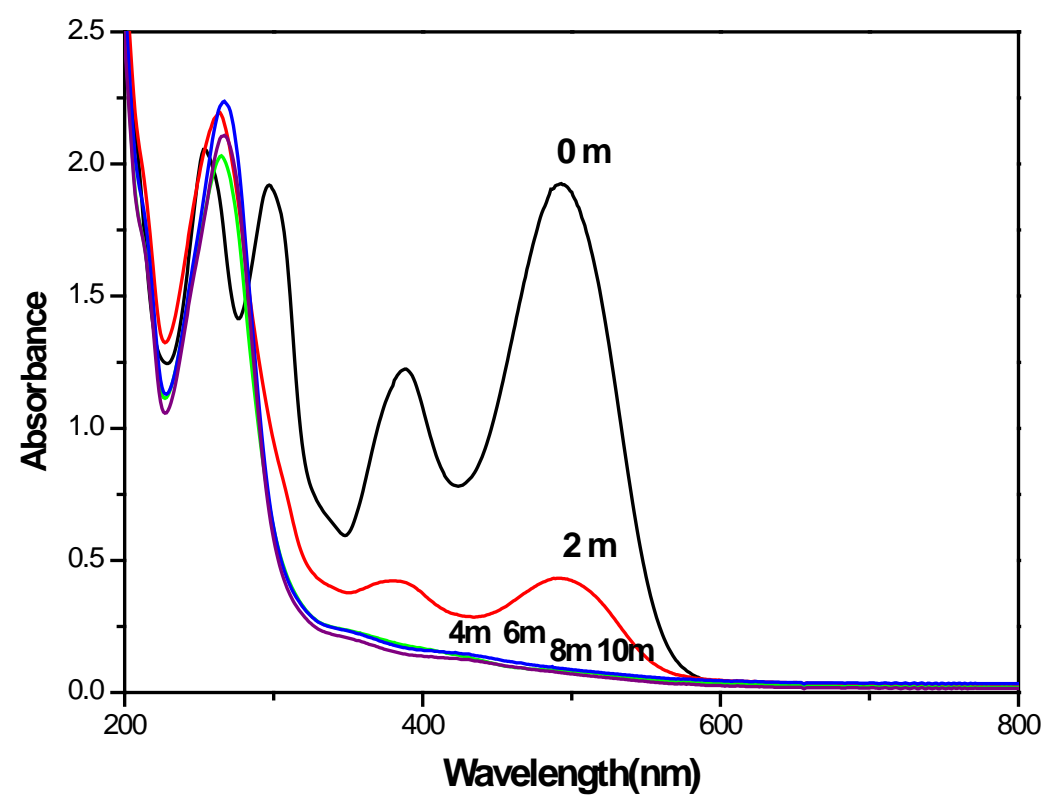

(b)

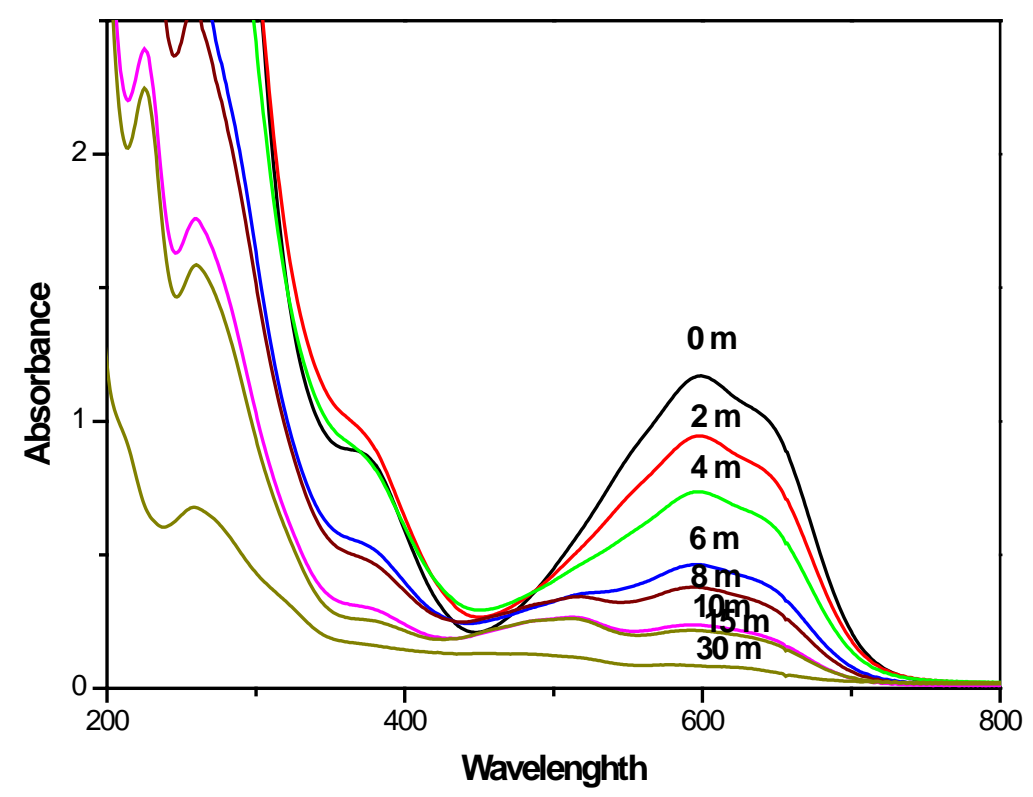

Figure 2. 

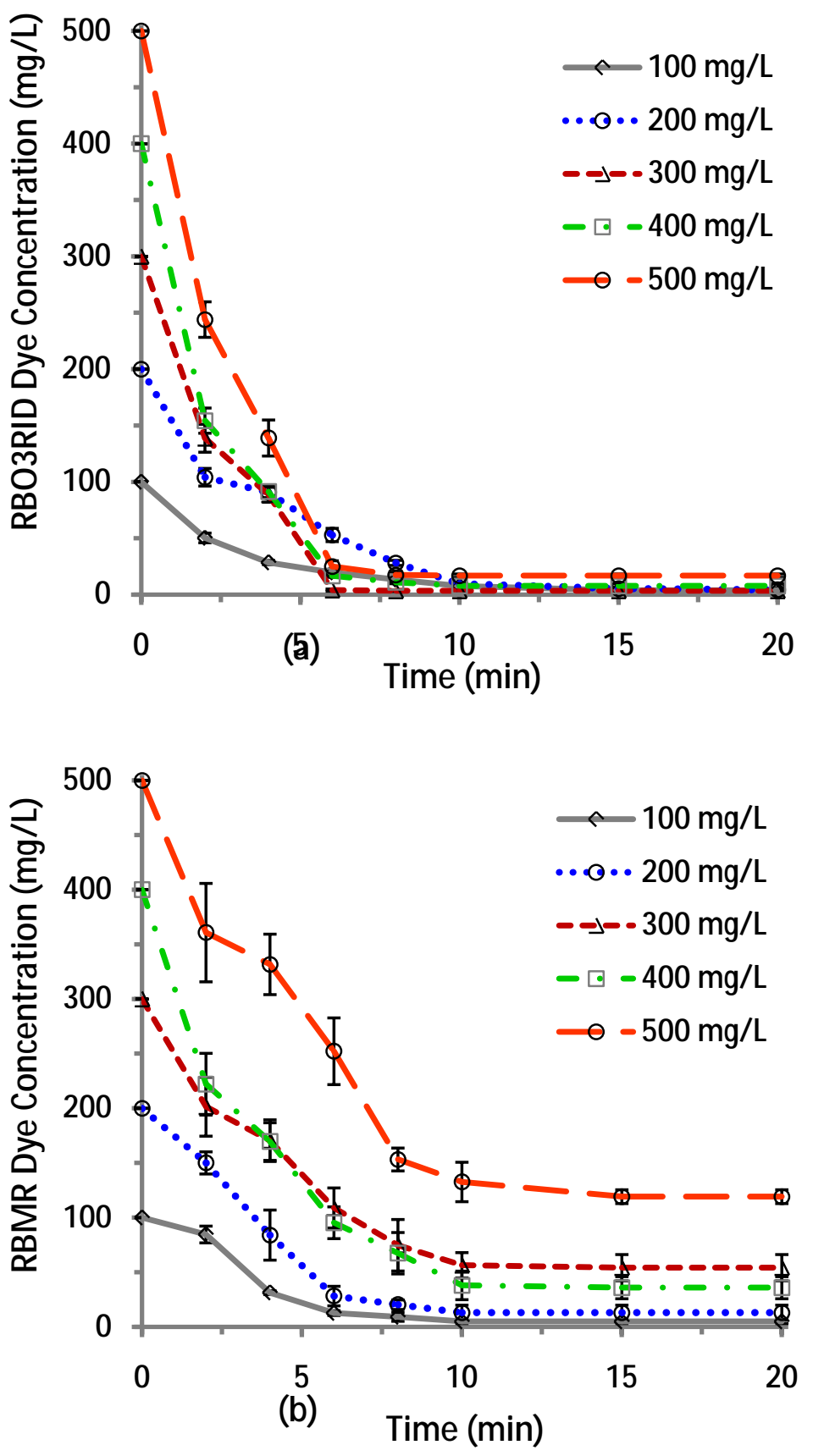

Figure 3. 
(a)
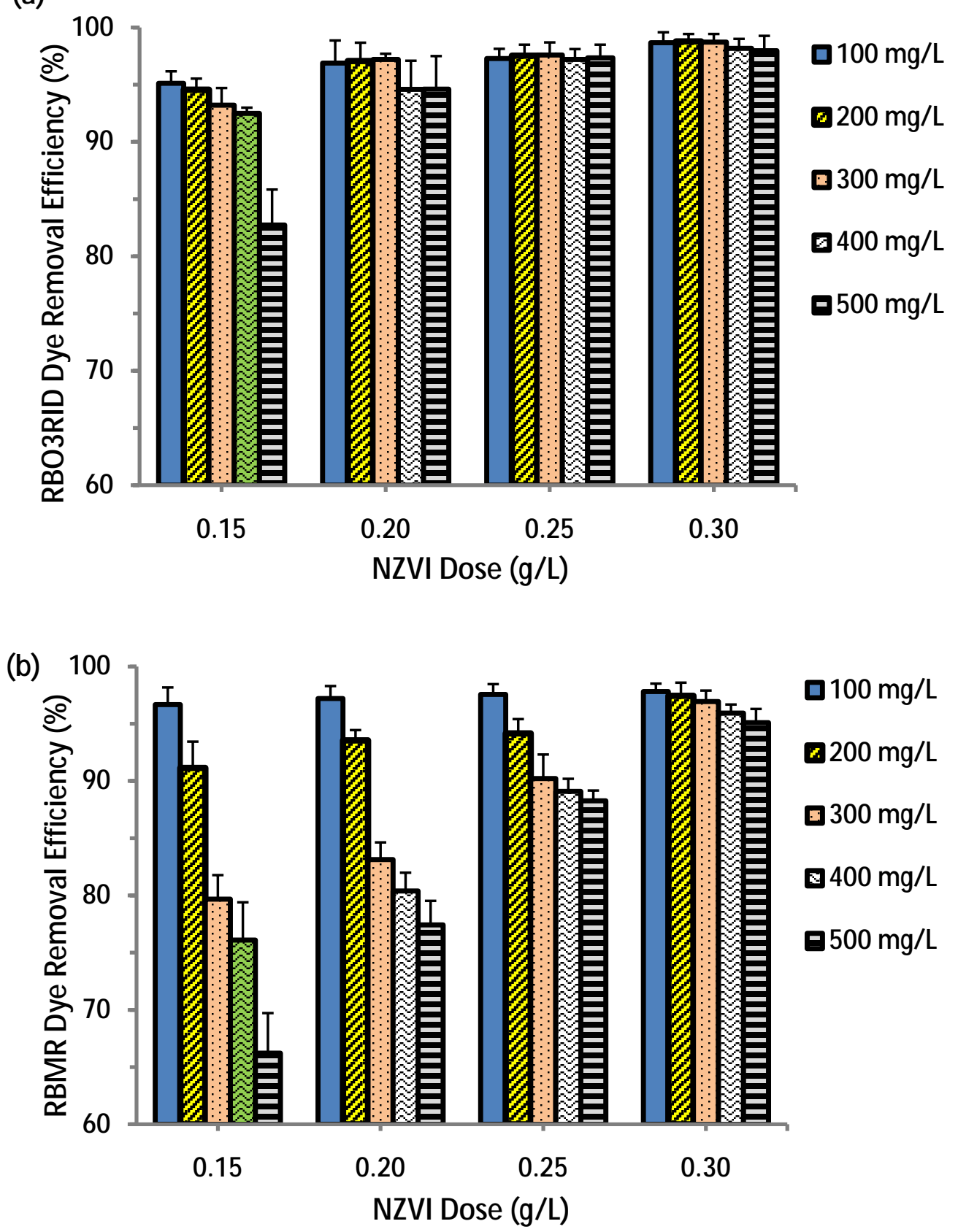

Figure 4. 


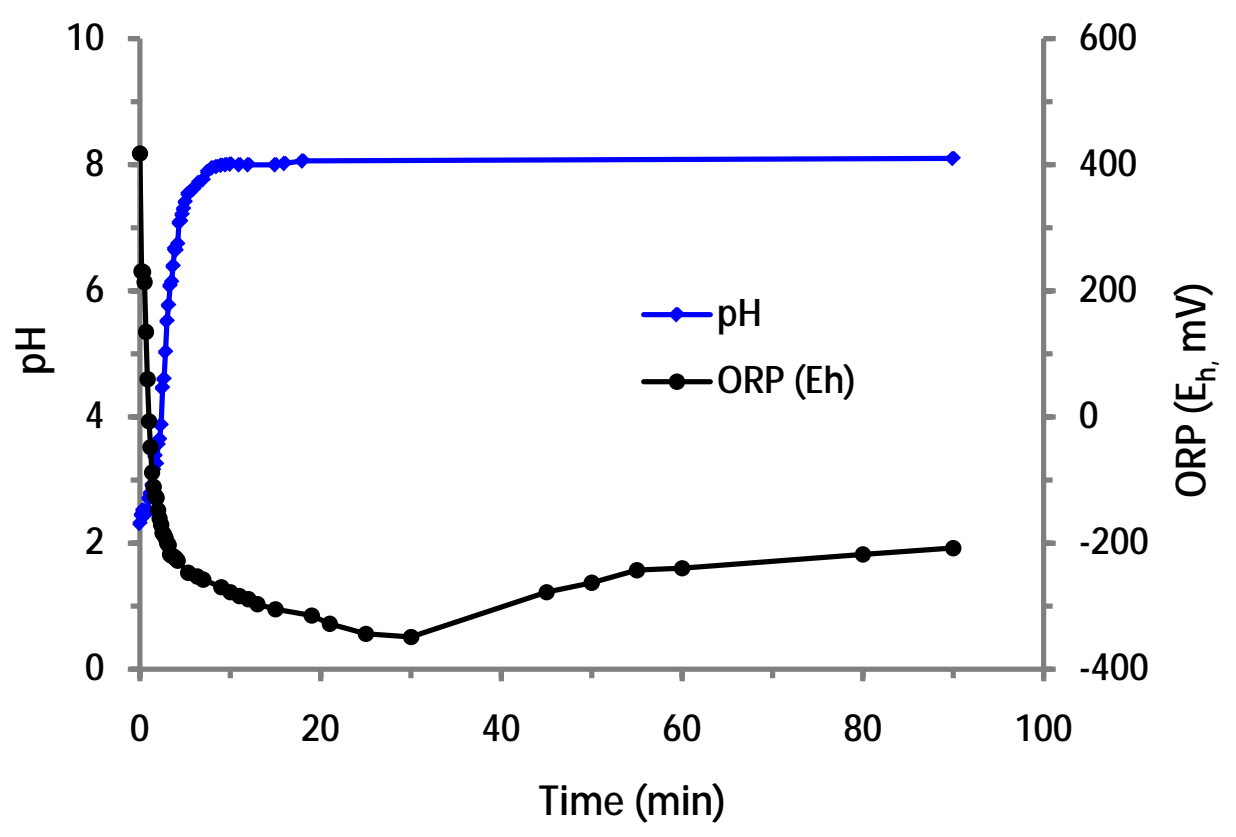

Figure 5. 

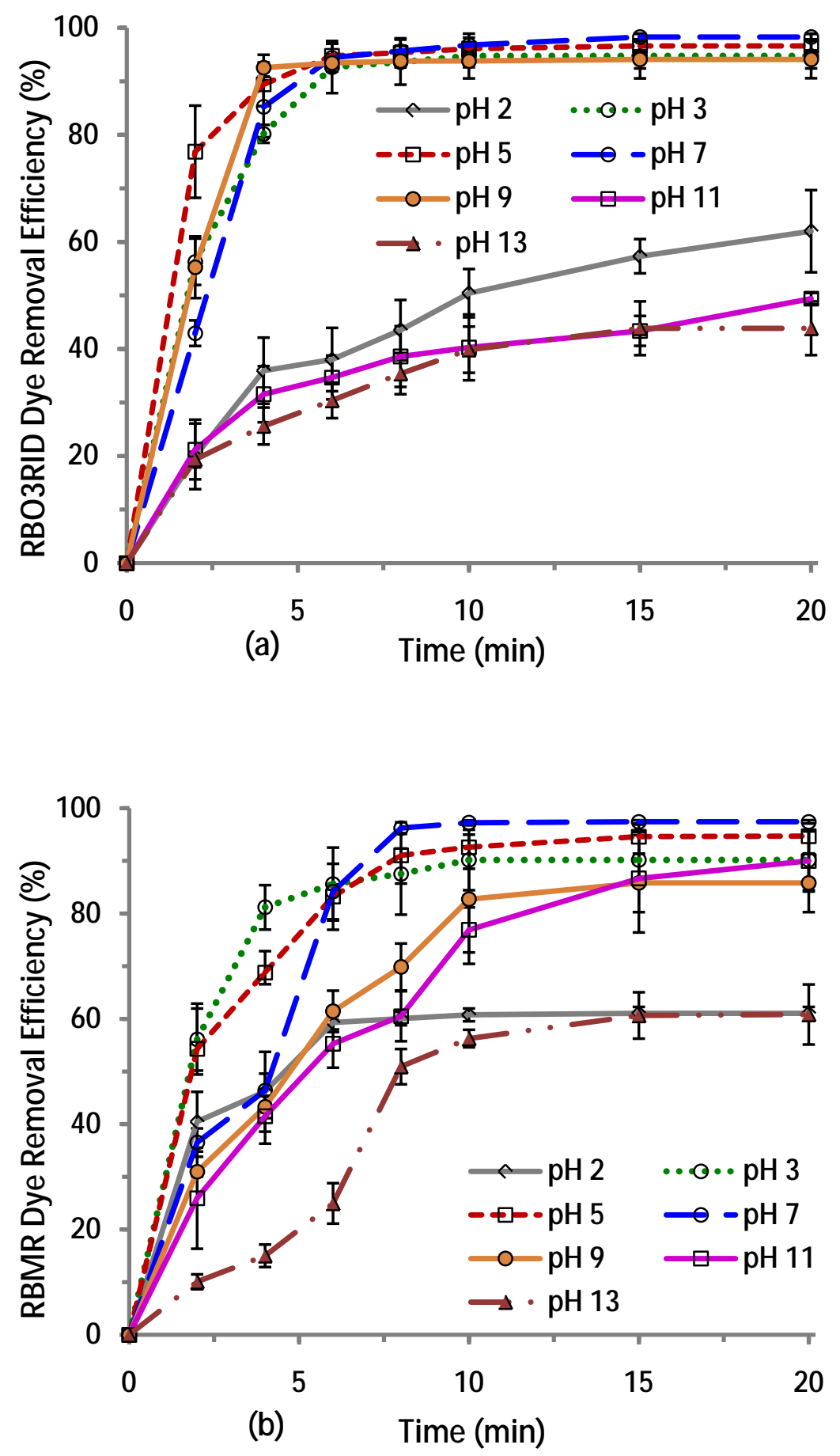

Figure 6. 


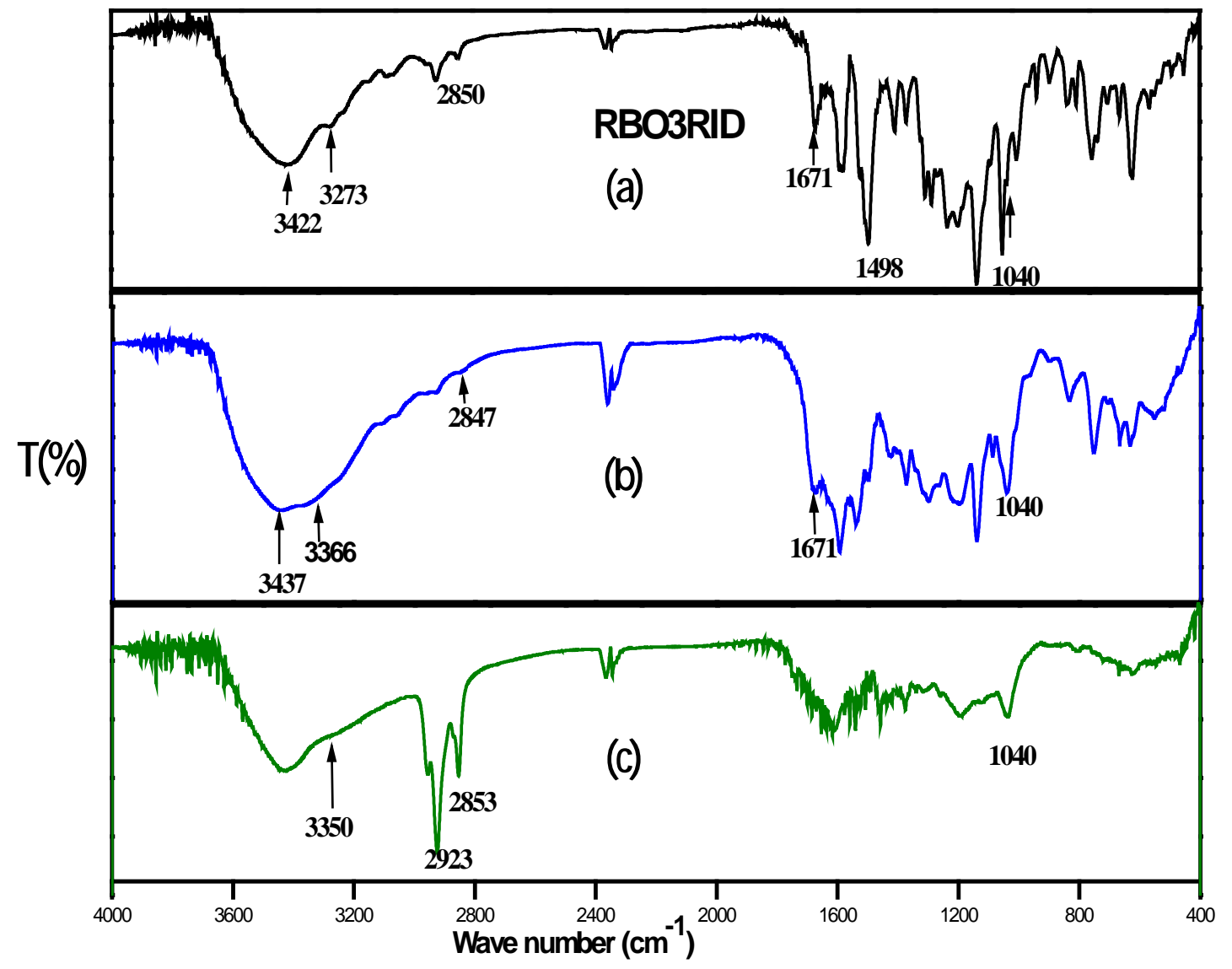

Figure 7. 


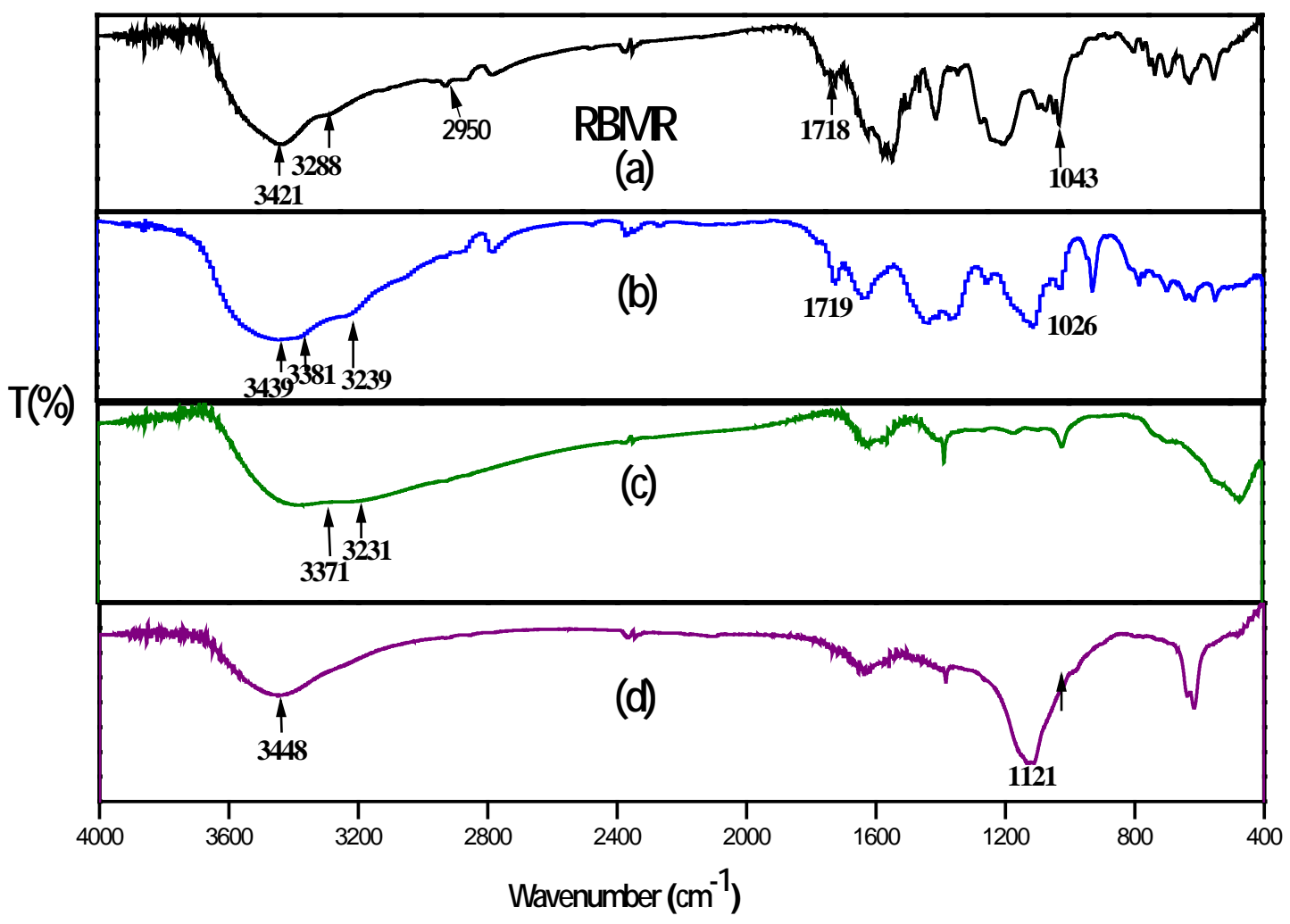

Figure 8. 
Graphical Abstract

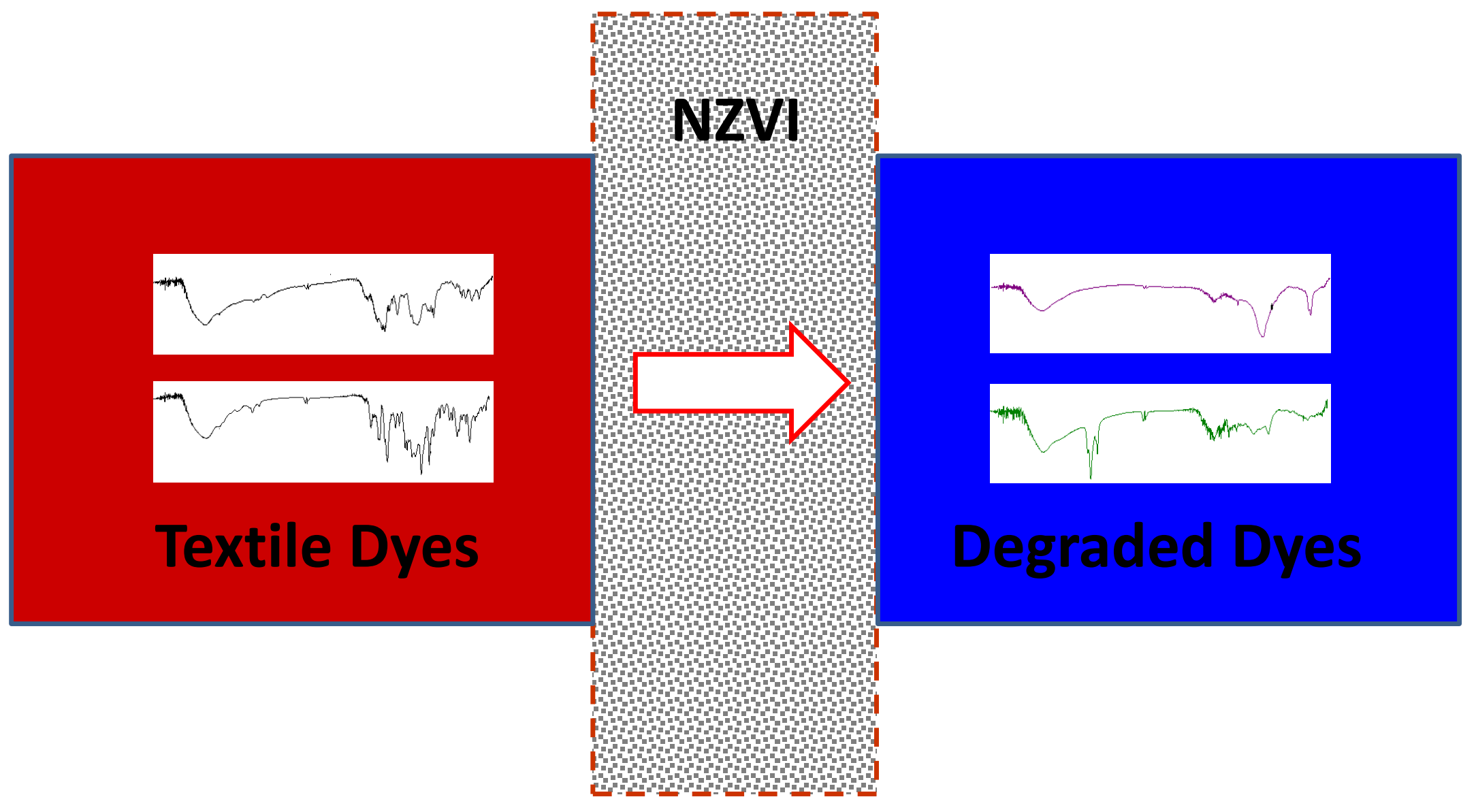

